\title{
CAPITAL INTELECTUAL E RENTABILIDADE DAS “MELHORES EMPRESAS PARA TRABALHAR"
}

\author{
INTELLECTUAL CAPITAL AND RETURN OF THE "BEST COMPANIES TO \\ WORK FOR"
}

\section{CAPITAL INTELECTUAL Y LA RENTABILIDAD DE LAS “MEJORES EMPRESAS PARA TRABAJAR"}

\section{Thaiseany de Freitas \\ Rêgo, Universidade \\ Federal Rural do \\ Semiárido (UFERSA), \\ Mossoró, RN, Brasil \\ Ana Maria Magalhães \\ Correia, Universidade \\ Federal Rural do \\ Semiárido (UFERSA), \\ Mossoró, RN, Brasil \\ Andrea Kaliany da \\ Costa Lima, \\ Universidade do \\ Estado do Rio Grande do Norte (UERN), Mossoró, RN, Brasil \\ Carlos Olavo Quand, Pontifícia Universidade \\ Católica do Paraná, Paraná, Brasil}

Artigo Submetido em 01.06.2016. Ajustado e Aprovado em 16.02.2018. Avaliado pelo processo de double blind review

e-mail para contato: thaiseany@yahoo.com.br

\begin{abstract}
RESUMO
A perspectiva de que os recursos intangíveis influenciam a criação de valor motivou este estudo sobre a relação entre a evidenciação de itens de capital intelectual e a rentabilidade dos ativos (ROA) das "Melhores empresas para você trabalhar" listadas no Guia 2012 da Você S/A. A análise de dados em painel, com 169 observações e uso dos MQG, para efeitos aleatórios, se mostra como a amis adequada para medir o poder explicativo das variáveis, com um DW de 0,8817. Constatou-se que $61,5 \%$ dos itens de capital intelectual são evidenciados no Relatório de Administração. A evidenciação do capital intelectual contribui estatisticamente ( $p$-value $=0,0784$ ) para o aumento do índice de rentabilidade dos ativos, explicando $2,23 \%$. Isso indica que, quanto maior o número de itens sobre o capital intelectual evidenciados, maior será o ROA. As empresas do setor de energia elétrica detêm um poder explicativo de $8,1 \%$ na relação entre evidenciação de capital intelectual e ROA, enquanto o grupo com as demais empresas aponta uma relação inversa no poder explicativo das variáveis.
\end{abstract}

Palavras-chave: Evidenciação. Capital intelectual. Rentabilidade dos ativos.

\section{ABSTRACT}

The notion that intangible assets influence value creation motivated this study about the relation between the disclosure of intellectual capital and the return on assets (ROA) of the "Best companies to work for" listed in the 2012 Guide of Você $S / A$ magazine. The panel data analysis, with 169 observations and use of the MQG, for random effects, is shown to be the most adequate to measure the explanatory power of the variables, with a DW of 0.8817 . It was found that $61.5 \%$ of the items of intellectual capital disclosed were in the Annual Report. The disclosure of intellectual capital items contribute statistically ( $p$-value $=0.0784$ ) to the increase in the profitability index of the assets, accounting for $2.23 \%$. This indicates that the greater the number of intellectual capital items that are disclosed, the higher the ROA. It was verified that the companies in the electricity sector hold an explicative power of $8.1 \%$ in the relationship between disclosure of intellectual capital and return on assets, while the group with the other companies indicates an inverse relationship in the explanatory power of the variables analyzed.

Keywords: Disclosure. Intellectual Capital. Return on assets. 


\title{
QREUNIR
}

\begin{abstract}
RESUMEN
La perspectiva de que los intangibles influyen en la creación de valor motivó a este estudio sobre la relación entre la evidenciación de artículos de capital intelectual y la rentabilidad de los activos (ROA) de las "Mejores empresas para trabajar" listadas en el "Guia 2012" de la revista "Você S/A". El análisis de datos en panel, con 169 observaciones y uso de los MQG, a efectos aleatorios, se muestra como la más adecuada para medir el poder explicativo de las variables, con un DW de 0,8817 . Se comprobó que $61,5 \%$ de los artículos de capital intelectual se evidencian en el informe de administración. La evidenciación del capital intelectual contribuye estadísticamente ( $p$-value $=0,0784$ ) para el aumento del índice de rentabilidade de los activos explicando 2,23\%. Esto indica que, cuanto mayor el número de artículos evidenciados sobre el capital intelectual, mayor será el ROA. Las empresas del sector de energía eléctrica tienen um poder explicativo de $8,1 \%$ en la relación entre la evidenciación de capital intelectual y la ROA, mientras que el grupo com las otras empresas muestra una relación inversa en poder explicativo de las variables.
\end{abstract}

Palabras-clave: Evidenciación. Capital intelectual. Rentabilidad de los activos.

\section{INTRODUÇÃO}

O ambiente de negócios vem apresentando mudanças decisivas nos últimos anos, trazendo à tona uma nova era, cuja fonte fundamental de riqueza centra-se no conhecimento e na informação (STEWART, 1998). Nesse contexto, ao alinhar esse modelo com à economia do conhecimento, o foco volta-se para o capital intelectual. Isso tem estimulado o surgimento de um novo conceito de organização, moldado nos pressupostos da maximização e alavancagem do conhecimento, que torna as organizações empresariais bem-sucedidas (CRICELLI; GRIMALDI; HANANDI, 2011).

A importância do conhecimento nas organizações passa, necessariamente, pela compreensão do conceito de capital intelectual, o que abrange elementos intangíveis. Um deles é o componente humano, que detém os recursos do conhecimento e aqueles gerados com a sua aplicação. Um exemplo disso são as tecnologias desenvolvidas para a inovação, marca, estilo de gestão, processos administrativos e imagem corporativa (ANTUNES; LEITE, 2008).

Na busca de diferenciais competitivos, Edvinsson e Malone (1998) afirmam que as organizações começam a prestar atenção em seus ativos ocultos. Ou seja, aqueles que apesar de não possuírem existência física, geram valor. Nesse contexto, Bontis (2001) destaca o uso dos termos capital intelectual, capital do conhecimento, organizações de conhecimento, organizações de aprendizagem, aprendizagem organizacional, era da informação, era do conhecimento, ativos de informação, ativos intangíveis, gerenciamento intangível, valor oculto e capital humano. É a partir da mensuração desse tipo de ativo que a organização passa a ter uma visão sistêmica de seus valores. Contudo, para que esse tipo de ação ocorra faz-se necessário adotar medidas de desempenho de elementos críticos alinhados à estratégia de negócio (STEWART, 1997; EDVINSSON; MALONE, 1998; SVEIBY, 1998).

Em termos contábeis os modelos e processos organizacionais vêm sendo desenvolvidos com o intuito de lidar com os aspectos intangíveis. Salienta-se que isso tem estimulado a definição, mensuração e evidenciação de elementos intangíveis nas 


\section{(9REUNIR}

Demonstrações Contábeis (DEM), Notas Explicativas (NE) e Relatório da Administração (RA). Os mesmos têm se mostrado essenciais para retratar a situação das organizações (GASPARETTO, 2004; SOUZA et al., 2008).

Considerando a importância do conhecimento na construção de vantagens competitivas e que os intangíveis podem influenciar na criação de valor (PEREZ; FAMÁ, 2006), surge a seguinte questão de pesquisa: Há relação entre a evidenciação de itens de capital intelectual e a rentabilidade dos ativos das empresas de capital aberto, listadas pelo Guia $\mathbf{2 0 1 2}$ da Você S/A, entre as "Melhores empresas para você trabalhar"?

O estudo se fundamenta na concepção de Perez e Famá (2006), de que os ativos intangíveis influenciam na criação de valor das empresas. Para a determinação do índice de evidenciação de intangíveis relacionados ao capital intelectual $(\mathrm{Cl})$, foram adotados os itens condensados no estudo de Maçambanni et al. (2012) composto por três categorias e cinquenta e cinco subcategorias: Capital Humano (18), Capital Estrutural (17) e Capital de Clientes (20). Quanto ao indicador de ponderação para a relação proposta no estudo, considerou-se a rentabilidade sobre os ativos (Return on Assets - ROA).

Segundo informações extraídas do Portal do Guia 2012 da Você S/A, a eleição das "Melhores empresas para você trabalhar" é uma pesquisa anual, realizada desde 1997. A mesma permite ranquear as empresas nacionais, de acordo com as práticas adotadas para a gestão de pessoas. Salienta-se que a Fundação Instituto de Administração é responsável por sua determinação e só no ano de 2012 obteve o retorno de 136 mil profissionais e 505 empresas.

Ademais, o presente estudo discute a necessidade de divulgação de informações sobre os ativos intangíveis em instrumentos obrigatórios. Outro ponto interessante, diz respeito à proposição de um índice de evidenciação sobre o capital intelectual e identificar o tipo de informação divulgada. O mesmo também permite apontar qual o poder explicativo de uma variável intangível na criação de valor.

\section{REFERENCIAL TEÓRICO}

\subsection{Capital Intelectual}

A dinâmica do cenário econômico e as constantes transformações no âmbito ambiental, social, econômico e político, são essenciais para uma reestruturação capitalista. A globalização e o avanço tecnológico aumentam a complexidade dessas relações e, por conseguinte, a competitividade entre as empresas (VASCONCELOS et al., 2009). Esses fenômenos tendem a valorizar as pessoas e suas capacidades intelectuais, bem como gerar vantagens competitivas.

Considerando o processo de criação de valor, nota-se uma proximidade entre os conceitos de gestão do conhecimento e o capital intelectual. Santiago Jr e Santiago (2007) explicam que a aplicação do conhecimento produz benefícios econômicos que impactam no valor das empresas. Todavia, o conceito de capital intelectual tende a ser mais amplo, pois abrange benefícios incorpóreos que agregam valor.

Oliveira e Beuren (2003) e Colauto e Beuren (2005) apontam que a expressão capital intelectual é encontrada com outras denominações. Para Nahapiet e Ghoshal (1998) ele depende das relações de confiança estabelecidas por um grupo ou comunidade, que se 


\section{(9)REUNIR}

organizam com a finalidade de alcançar objetivos comuns. Maçambanni et al. (2012), indica que a mesma representa o patrimônio do conhecimento, gestão do conhecimento, competências e habilidades, ativos intangíveis, capacidade de inovação, inteligência competitiva, gestão de pessoas e processos. Logo, representa um tipo de ativo capaz de gerar vantagem competitiva (STEWART, 1998).

Lev e Daum (2004) definem ativo intangível como um direito a benefícios futuros e que não possui corpo físico ou financeiro. Para Hendriksen e Van Breda (2009) os ativos intangíveis carecem de substância. Como tais, esses ativos precisam ser reconhecidos sempre que preenchem os requisitos para a definição de ativos, forem mensuráveis, relevantes e precisos.

Upton Jr (2003) destaca os ativos intangíveis como recursos não físicos, que tem potencial para gerar benefícios econômicos, e são adquiridos por meio de troca ou desenvolvidos pela organização. Os valores desses itens se fundamentam em custos identificáveis, que têm vida limitada, possuem valor de mercado estimado e podem pertencer ou ser controlado pela entidade. Os ativos intangíveis costumam ser compreendidos como todo e qualquer elemento de uma organização, que existe além dos ativos monetários e tangíveis (NASCIMENTO et al., 2012).

Hendriksen e Van Breda (2009) comentam que os intangíveis podem ser identificáveis ou não identificáveis. Sempre que for possível the atribuir um nome, como patente, por exemplo, indica que se trata de um ativo intangível identificável. Caso contrário, trata-se de um ativo não identificável. O exemplo mais comum de ativo intangível não identificável é o goodwill, o que Santiago Jr e Santiago (2007) definem como sendo a diferença entre o valor de mercado e o valor contábil.

Stewart (1998), assim como Edvinsson e Malone (1998) e Schmidt e Santos (2009), destacam que todos os intangíveis representam capital intelectual. Bontis (1998) entretanto, procura fazer a distinção entre intangíveis e capital intelectual. Para ele, capital intelectual não inclui ativos de propriedade intelectual, marcas registradas, patentes e vários outros direitos passíveis de registros na contabilidade. Isso, porque, o compreende que o capital intelectual não é apenas um intangível estático, mas sim um processo ideológico. Esse tipo de capital comporta um conjunto de conhecimentos e informações da organização, que agregam valor ao produto e/ou serviço (COUTO, 2009). Como uma consequência da definição dos intangíveis, estes podem ser subdivididos, de acordo com a taxonomia abordada por Stewart (1998) e Edvinsson e Malone (1998).

De acordo com Stewart (1998), o Capital Intelectual, pode ser dividido em Capital Humano (CH), Capital Estrutural (CE) e Capital do Cliente (CC). Bontis e Fitz-Enz (2002) destacam a interação dessas três dimensões no processo de criação de valor dentro das organizações e argumentam sobre a existência de relações causais, nas quais o capital humano é influenciado pelo capital estrutural e pelo capital relacional. Nessa perspectiva, o $\mathrm{CH}$ representa uma fonte de inovação e renovação, que revestida de talento, habilidade e conhecimento dos empregados. Todavia, para o compartilhar e transmitir cabe utilizar elementos estruturais, o CE. Os mesmos englobam sistemas de informações, patentes, processos, banco de dados e outros ativos intangíveis internos, que funcionam como uma espécie de amplificador.

O CC, segundo Stewart (1998) simboliza o valor dos relacionamentos de uma empresa com as pessoas com as quais faz negócio, o que diz respeito basicamente ao 
relacionamento com os clientes e fornecedores (COUTO, 2009). Para Backes, Ott e Wiethaeuper (2005), o capital intelectual é formado pela sinergia entre $\mathrm{CH}, \mathrm{CE}$ e CC. Desse modo, o Capital Intelectual compreende o $\mathrm{CH}$ e tudo o que deriva da aplicação do intelecto.

O Capital de Inovação (CIN), segundo Nagano, Matheus e Merlo (2005) está relacionado àquilo que garante a capacidade de criação e renovação da empresa. O CIN compreende a propriedade intelectual da empresa, que cuida das atividades de pesquisa e desenvolvimento (P\&D). O Capital de Processos (CP) representa a estruturação dos processos, técnicas e procedimentos realizados dentro da empresa, assim como a tecnologia necessária para suportá-los.

\subsection{Evidenciação do Capital intelectual}

Um dos objetivos da contabilidade consiste em gerar informações úteis para a tomada de decisão (HENDRIKSEN; VAN BREDA, 2009). Desta forma, destaca-se que o processo de evidenciação é capaz de modificar o entendimento do indivíduo sobre o contexto ou o objeto de análise. Logo, a evidenciação ou disclosure, funciona como um agente que facilita a tomada de decisão e reduz a assimetria da informação.

Brammer e Pavelin (2008) e Santos et al. (2010) destacam que os relatórios contabeis são importantes para apresentar informações precisas e objetivas sobre a organização. Para analisar os aspectos relacionados à divulgação, Dye (2001) e Hendriksen e Van Breda (2009) enquadram o disclosure em dois extremos: obrigatório e voluntário. O primeiro contempla a divulgação de informações, de acordo com os aspectos legais. A evidenciação voluntária abarca elementos sem caráter compulsório e oferecem informações adicionais sobre as atividades corporativas (BONTIS, 2001).

Lambert, Leuz e Verrecchia (2006) destacam que as pesquisas que abordam disclosure se dividem em três categorias. A primeira retrata a divulgação por meio da associação (association-based disclosure), analisando o disclosure voluntário e o comportamento dos acionistas. A segunda categoria é conhecida como pesquisa sobre divulgação, fundamentada no julgamento (discretionary-based disclosure), que investiga as razões que impulsionam a divulgação de determinada informação. Já a terceira categoria considera a divulgação baseada na eficiência (efficiency-based disclosure).

Embora a evidenciação se refira aos relatórios empresariais, merecem destaque as: Demonstrações contábeis, Informações entre parênteses, Notas explicativas, Quadros e demonstrativos suplementares, Comentários do auditor, Relatório da administração, Relatório de sustentabilidade, Balanço social. Isso, porque, embora disponham de informações distintas, o seu propósito consiste em auxiliar na tomada de decisão.

Quando se trata da evidenciação do capital intelectual, Backes, Ott e Wiethaeuper (2005) destacam que a divulgação de informações dessa natureza não é obrigatória. Apesar disso, cada empresa tem um propósito informacional quando publicam um demonstrativo. Logo, a evidenciação depende da organização e do tipo de usuário que busca atender (MAÇAMBANNI et al., 2012).

Uma tendência tem se manifestado sobre a divulgação voluntária de informações sobre as práticas de capital intelectual. A partir dessa constatação, destaca-se a necessidade de redução da assimetria informacional. Nessa perspectiva, quando a empresa se preocupa 


\section{QREUNIR}

em atender a demanda do ambiente e melhorar o valor de suas ações, as mesmas tendem a divulgar informações dessa natureza (MATOS et al., 2009).

\subsection{Rentabilidade dos Ativos (ROA)}

Os estudos acadêmicos e a demanda do mercado, ao compor avaliações sobre a criação de valor, estimulou o desenvolvimento de algumas técnicas de avaliação de desempenho. As mesmas permitem medir como se encontra a situação econômica, financeira e patrimonial da organização. Dentre os principais índices utilizados nesse processo, destacam-se: liquidez, endividamento, atividade e rentabilidade (MEDEIROS; CRUZ; ANDRADE, 2009).

Segundo Vieira et al. (2012) a rentabilidade mede o quanto uma empresa está sendo lucrativa ou não, em relação ao capital investido. Destaca-se que esse tipo de índice permite evidenciar qual o resultado obtido com as operações realizadas pela organização quanto ao Retorno sobre o investimento (ROI), Retorno sobre ativos (ROA) e Retorno sobre patrimônio líquido (ROE). No entanto, dado o objetivo desse trabalho, o foco é a análise do ROA.

O ROA se configura como uma medida que trata do potencial e capacidade de geração de lucro por parte da empresa. Esse indicador sinaliza uma medida de desempenho a ser comparada ano a ano (MEDEIROS; CRUZ; ANDRADE, 2009). Assaf Neto, Lima e Araújo (2008, p. 76) apontam que o ROA "revela o retorno produzido pelo total das aplicações realizadas por uma empresa em seus ativos".

Wernke e Lembeck (2006) e Vieira et al. (2012) comentam que o uso do ROA pode proporcionar alguns benefícios, tais como: identificar como a margem do lucro aumenta ou se deteriora; medir a eficiência dos ativos permanentes em produzir vendas; avaliar a gestão do capital de giro; estabelecer medidas que auferem a habilidade do gestor para controlar custos e despesas, em função do volume de vendas; comparar as medidas de eficiência citadas anteriormente e estabelecer o patamar máximo de custo de captação de recursos que a empresa pode suportar.

\section{ASPECTOS METODOLÓGICOS}

Fundamentado na proposição de Perez e Famá (2006), ao relacionar os intangíveis com o valor das empresas, o estudo busca responder a seguinte questão de pesquisa: Há relação entre a evidenciação de itens de capital intelectual e a rentabilidade dos ativos das empresas de capital aberto, listadas pelo Guia 2012 da Você S/A, entre as "Melhores empresas para você trabalhar"?. Para tanto, foram considerados elementos intangíveis de capital intelectual (MAÇAMBANNI et al., 2012) e o valor do ROA (ASSAF NETO, 2007). Tais prerrogativas propiciaram o ajuste da proposta de estudo ao campo de pesquisa selecionado e a coleta dos dados.

Para a determinação das empresas a serem estudadas, analisou-se as informações pertinentes as 150 organizações listadas no Portal do Guia 2012 da Você S/A, entre "As melhores empresas para você trabalhar". Ao analisar o ranking, foram selecionadas as organizações que dispunham de ações ordinárias negociadas na BM\&FBOVESPA, atualmente denominada de "Brasil, Bolsa, Balcão" (B3). Isso, porque, empresas com ações negociadas em bolsa têm a obrigatoriedade de divulgar, anualmente, os relatórios referentes a: Balanço 
Patrimonial (BP), Demonstração do Resultado do Exercício (DRE), Notas Explicativas (NE) e Relatório da Administração (RA) (Tabela 1).

Tabela 1: Melhores empresas para você trabalhar, com ações na B3

\begin{tabular}{|c|c|c|c|c|}
\hline Empresas & IFT* & IQAT** & IQGP*** & Período \\
\hline AES Sul & 79,2 & 82,9 & 70,7 & 1997-2012 \\
\hline Amil Resgate Saúde & 84 & 85,8 & 79,9 & 2006-2012 \\
\hline Ampla & 78,5 & 73,2 & 90,9 & 1997-2012 \\
\hline Banco Bradesco & 75,1 & 77,1 & 70,6 & 1997-2012 \\
\hline CEMAR & 76,7 & 75,6 & 79,4 & 2000-2012 \\
\hline Cielo & 78,8 & 77,4 & 82,1 & 2008-2012 \\
\hline Coelce & 79,9 & 74,6 & 92,2 & 1997-2012 \\
\hline CPFL Energia S.A. & 74,9 & 74,2 & 76,6 & 1999-2012 \\
\hline Ecorodovias & 72,6 & 77,8 & 60,6 & 2002-2012 \\
\hline Elektro & 92,5 & 95,4 & 85,8 & 1998-2012 \\
\hline Eletrobras & 77,9 & 78 & 77,8 & 1997-2012 \\
\hline Embraer & 82,8 & 84,4 & 78,9 & 2005-2012 \\
\hline ETERNIT & 72 & 73,3 & 68,9 & 1997-2012 \\
\hline Fras-le & 81,8 & 77,5 & 91,6 & 1997-2012 \\
\hline Gerdau & 81 & 81,7 & 79,3 & 1997-2012 \\
\hline Magazine Luiza & 78,6 & 78,5 & 78,6 & 2010-2012 \\
\hline Randon & 79,5 & 79,4 & 80 & 1997-2012 \\
\hline TRACTEBEL ENERGIA & 79,7 & 81,7 & 75,1 & 1998-2012 \\
\hline MÉDIA & 79,2 & 79,4 & 78,8 & - \\
\hline
\end{tabular}

* Índice de felicidade no trabalho. ** Índice de qualidade no ambiente de trabalho. *** Índice de qualidade na gestão de pessoas.

Fonte: Adaptado do Portal do Guia 2012 da Você S/A.

Da lista de empresas estudadas, fez-se necessário realizar um recorte temporal considerando a disponibilidade dos relatórios necessários para subsidiar o estudo. Para tanto, adotou-se como critério de seleção, a permanência contínua das organizações na B3, entre os anos de 2000 e 2012, o que resultou em um recorte temporal de 13 anos. Além disso, à disponibilidade de informações sobre o ROA no software Economática ${ }^{\circledR}$, também foi observada.

Analisando as empresas objeto de estudo, contatou-se que das 150 listadas entre "As melhores empresas para você trabalhar", 18 dispunham das informações necessárias. Logo, visando manter o maior número de observações com informações contínuas, a amostra culminou em 13 empresas, marcadas em negrito na Tabela 1. Concluída essa etapa, e com o propósito de construir o índice de evidenciação de capital intelectual, adotou-se os itens sugeridos por Maçambanni et al. (2012), como ilustrado no Quadro 1.

Quadro 1: Itens de Capital Intelectual utilizados para determinar o "Índice de evidenciação"

\begin{tabular}{|l|l|l|l|}
\hline \multicolumn{1}{|c|}{ Capital humano } & \multicolumn{1}{|c|}{ Capital estrutural } & \multicolumn{2}{c|}{ Capital de clientes } \\
\hline 1. Ativo/recurso & 1. Propriedade intelectual & 1. Carteira de clientes \\
2. Incentivo a novas ideias & 2. Patentes & 2. Lealdade/fidelidade dos clientes \\
3. Investimentos em educação de & 3. Direitos autorais & 3. Captação de clientes \\
funcionários & 4. Marcas & 4. Retenção de clientes \\
4. Treinamento/desenvolvimento/c & 5. Inovação/P\&D & 5. Satisfação do cliente \\
apacitação & 6. Tipos/qualidade dos produtos e & 6. Investimentos em TI/cliente \\
5. Retenção/captação de talentos & & serviços & 7. Suporte ao cliente \\
6. Qualificação profissional & 7. Cultura & 8. Parcerias clientes/fornecedores \\
\hline
\end{tabular}




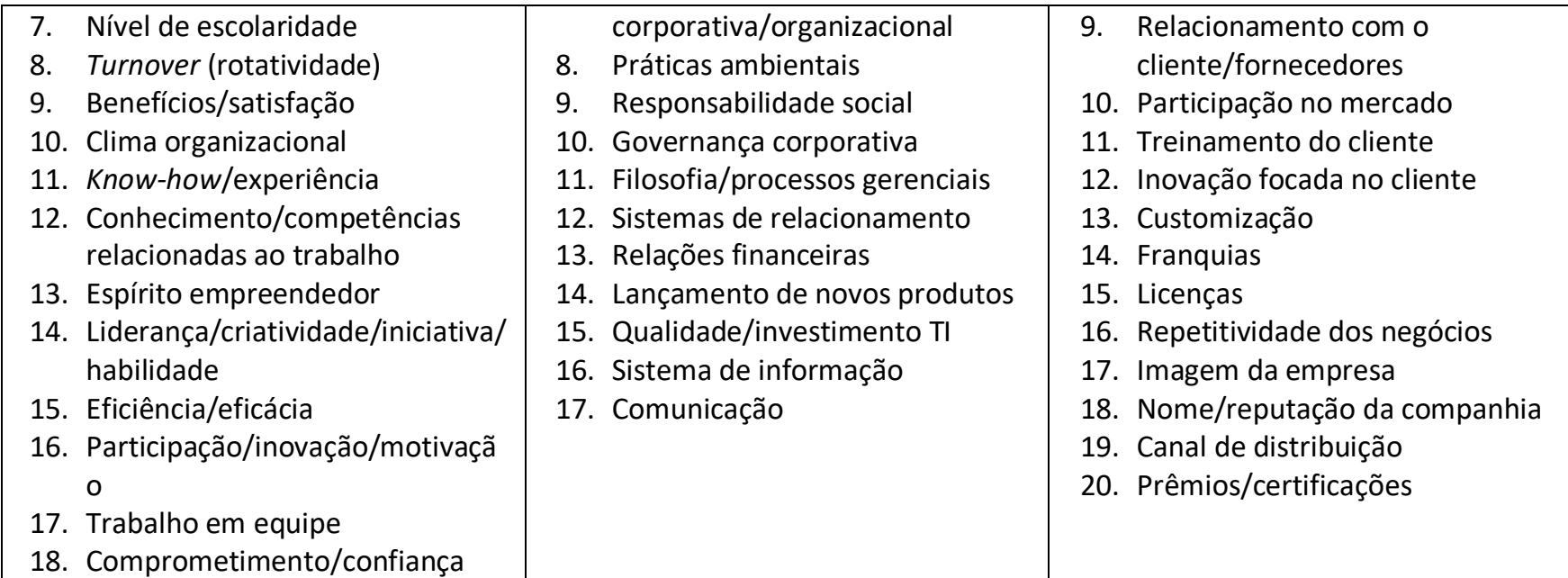

Fonte: Adaptado de Maçambanni et al. (2012).

Com base nos referidos itens, foi realizada uma análise de conteúdo dos relatórios, de modo a identificar quais deles foram publicados pelas empresas objeto de estudo. Nesse sentido, para determinar o "Índice de evidenciação", atribuiu-se 1 (um) ponto, quando o item estava divulgado, e 0 (zero), quando não apresentado. Após isso, somou-se a pontuação obtida por cada empresa e dividiu-se o montante pelo número possível de itens a serem evidenciados (55). Em caráter complementar, e com o intuito de detectar qual a natureza das informações evidenciadas nas dimensões do capital intelectual, foi analisado ainda se as mesmas priorizavam a divulgação de informações monetárias (2) ou qualitativas (3). Logo, foi possível detectar se as empresas se preocupavam em mensurar seus investimentos com capital intelectual ou se apenas anunciavam as suas intenções.

Com a coleta dos dados e determinação do índice de evidenciação, procedeu-se com a extração de informações referentes ao ROA, no período de 2000 a 2012, com o auxílio do Economática ${ }^{\circledR}$. Ademais, para identificar se a proposição estabelecida detém um real poder explicativo, foram coletadas algumas variáveis de controle: ativo total e lucro líquido. De posse dos índices, os dados foram empilhados para a realização da análise com dados em painel, que resultou em 169 observações, ou seja, 13 empresas em 13 períodos. Para subsidiar a análise, adotou-se o pacote estatístico do Eviews Statistic Software ${ }^{\circledR}$ (versão 5.0).

\section{APRESENTAÇÃO E ANÁLISE DOS RESULTADOS}

Antes de iniciar a análise dos dados, procedeu-se com o estudo exploratório dos mesmos (HAIR JR et al., 2009), de modo a averiguar a existência de missing values (dados perdidos) e outliers (observações atípicas). Ao proceder com a mineração dos dados, constatou-se que não há elementos faltantes e que existe um dado atípico, referente ao valor negativo extraído para o ROA da AES Sul, no ano de 2002. Apesar dessa constatação, esse item não foi descartado da amostra, tendo em vista que o ROA das empresas costumam variar naturalmente, de acordo com suas políticas internas e a classificação setorial (ASSAF NETO, 2007; VIEIRA, et al., 2012).

Para atender ao propósito do estudo, as variáveis válidas foram sistematizadas de modo a subsidiar o uso de medidas de tendência central, como pode ser visualizado na Tabela 2. A partir da análise descritiva, observa-se que, de um total de 55 possibilidades de

8 


\section{(9)REUNIR}

divulgação de informações sobre capital intelectual, as empresas pesquisadas atingiram um índice de evidenciação médio de 0,43.

Tabela 2: Estatística descritiva

\begin{tabular}{l|c|c|c|c}
\hline & $\begin{array}{c}\text { Índice de } \\
\text { Evidenciação }\end{array}$ & ROA & $\begin{array}{c}\text { Variação do Ativo } \\
\text { Total }\end{array}$ & $\begin{array}{c}\text { Variação do Lucro } \\
\text { Líquido }\end{array}$ \\
\hline Média & 0,43 & 7.44 & 0,04 & 0,17 \\
Mediana & 0,42 & 8,30 & 0,08 & 0,14 \\
Desvio-padrão & 0,23 & 10.49 & 0,64 & 3,65 \\
Variância & 0,02 & 110,13 & 0,42 & 13,32 \\
Valor mínimo & 0,08 & $-39,20$ & $-8,04$ & $-34,99$ \\
Valor máximo & 0,85 & 38,40 & 0,93 & 17,19 \\
\hline
\end{tabular}

Fonte: Dados da pesquisa.

Fazendo um contraponto do índice de evidenciação com os relatórios empresariais, constata-se que o RA $(61,48 \%)$ é o instrumento mais utilizado para retratar informações sobre capital intelectual. Nesse contexto, Souza et al. (2008) afirma que é comum as empresas adotarem o RA para evidenciar dados pertinentes ao capital intelectual, uma vez que seu conteúdo complementa as demonstrações contábeis tradicionais e reúne elementos informativos sobre a situação da empresa e suas perspectivas futuras. Logo, dada a subjetividade dos itens abordados no RA e em razão do mesmo não seguir um padrão e nem ser auditado, o seu conteúdo costuma apresentar uma visão otimista do gestor sobre sua própria atuação (YUTHAS; ROGERS; DILLARD, 2002).

Ponderando a respeito das informações divulgadas no RA, destaca-se que apesar desse relatório não ter a finalidade de apresentar informações quantitativas, $19,61 \%$ dos itens evidenciados são acompanhados de valores monetários. Dentre os itens listados por Maçambanni et al. (2012) e que são evidenciados com recursos pelas empresas pesquisadas, tem-se: $\quad \mathrm{CH} \quad-\quad$ investimentos em educação de funcionários, treinamento/desenvolvimento/capacitação, qualificação profissional, e participações/inovação/motivação; CE - práticas ambientais, e relações financeiras; e CR carteira de clientes, e canal de distribuição. Para Sousa et al. (2008) isso se justifica em razão do RA ter um caráter mais narrativo e ser elaborado com o propósito de atender os usuários externos.

O estudo chama a atenção para a pouca divulgação de itens sobre o capital intelectual nas demonstrações contábeis obrigatórias, BP e DRE $(8,97 \%)$, e em NE $(29,55 \%)$. Dentre os itens elencados por Maçambanni et al. (2012) e divulgados nesses relatórios empresariais, tem-se informações pertinentes a investimentos em: $\mathrm{CH}$ benefícios/satisfação, e participação/inovação/motivação; CE - relações financeiras, inovação/P\&D; e CR - participação no mercado. Segundo Antunes e Leite (2008) a ausência de dados financeiros sobre capital intelectual nos relatórios contábeis pode se dá em razão das empresas não destinarem recursos para essa área ou por tratarem dela de forma sigilosa.

No que diz respeito às $\mathrm{NE}$, destaca-se que as mesmas são elaboradas com o intuito de complementar as informações divulgadas nas demonstrações contábeis e contém informações sobre a composição de cada item (SANTOS et al., 2010). Considerando que esse relatório prioriza a divulgação de informações quantitativas, nota-se que $53,24 \%$ dos itens sobre capital intelectual estão vinculados a dados financeiros, como já observado no estudo 
de Bontis e Fitz-enz (2002). Dentre as principais informações divulgadas em NE, com valores monetários, tem-se: $\mathrm{CH}$ - benefícios/satisfação, eficiência/eficácia e participação/inovação/motivação; CE - relações financeiras, e inovação/P\&D; e CR licenças, e canal de distribuição.

Analisando o ROA e o conteúdo das demonstrações contábeis (ativo total e lucro líquido), verifica-se que a média do retorno sobre os ativos é de 7,44 . No que diz respeito à variação do ativo total, que é uma das variáveis de controle do estudo, destaca-se um aumento médio de $4 \%$ dentro do período analisado, para uma variância de 0,42 e desviopadrão de 0,64. Em relação à variação do lucro líquido, constatou-se um aumento médio de $17 \%$ do lucro líquido. Isso revela que as empresas pesquisadas estão operando em um mercado ativo e que lhes garante a entrada e saída de recursos (VIEIRA et al., 2012).

\subsection{Análise com dados em painel}

Considerando que o estudo apresenta um painel econométrico equilibrado, em que para cada unidade temporal há o mesmo número de observações, procedeu-se com a análise de dados em painel. Segundo Gujarati (2006), essa técnica possibilita captar a heterogeneidade $\left(a_{i}\right)$ e dinâmica dos regressores $\left(X_{i t}\right)$ de cada unidade de análise, bem como aumentar a eficiência dos estimadores $(\beta)$ e reduzir o erro $\left(\varepsilon_{i t}\right)$. Seguindo essa compreensão, o modelo com dados em painel $\left(Y_{i t}\right)$ segue a especificação da Equação 1:

$$
Y_{i t}=a_{i}+X_{i t} \beta+\varepsilon_{i t}
$$

Partindo da Equação 1, procedeu-se com o estudo da variável dependente (índice de evidenciação) e independente (ROA), para estimar a regressão com o uso do método dos Mínimos Quadrados Ordinários (MQO) e dos Mínimos Quadrados Generalizados (MQG). Destaca-se que os mesmos foram utilizados após empilhar os dados da regressão (GUJARATI, 2006). Nesse contexto, cabe frisar que esse tipo de análise se vale de relações associativas entre uma variável dependente e uma ou mais variáveis independentes.

Para garantir maior confiabilidade ao estudo, bem como eliminar efeitos espúrios e endógenos, foram incluídas variáveis de controle: ativo total e lucro líquido. A sua adoção visou reduzir possíveis problemas de colinearidade entre as variáveis, bem como garantir que haja uma relação entre o índice de evidenciação de capital intelectual e o ROA, como preconiza o estudo desenvolvido por Richieri (2007). Ademais, permite avaliar a eficiência ou ineficiência dos recursos destinados a composição do capital intelectual, sobre o desempenho organizacional (FIRER; WILLIAMS, 2003).

Considerando os elementos enumerados e partindo-se para o resultado das regressões, apresentam-se os modelos estimados com o painel sem efeitos, com efeitos fixos e com efeitos aleatórios, na Tabela 3. Segundo Gujarati (2006) a adoção de efeitos fixos permite analisar os dados agrupados, desconsiderando as dimensões de tempo e espaço, enquanto que os efeitos aleatórios corrigem possíveis erros e permite avaliar a dinâmica do comportamento das variáveis. Como destaca Duarte, Lamounier e Takamatsu (2007), esse tipo de técnica possibilita do controle da heterogeneidade dos dados e auxilia no processo decisório. 
Tabela 3: Modelos estimados para as 13 empresas

\begin{tabular}{|c|c|c|c|c|c|c|}
\hline \multirow[b]{2}{*}{ Variáveis } & \multicolumn{2}{|c|}{$\begin{array}{l}\text { MQO Agrupado } \\
\text { (sem efeitos) }\end{array}$} & \multicolumn{2}{|c|}{ MQO com Efeitos Fixos } & \multicolumn{2}{|c|}{$\begin{array}{l}\text { MQG com Efeitos } \\
\text { Aleatórios }\end{array}$} \\
\hline & Coef. & p-value & Coef. & p-value & Coef. & p-value \\
\hline $\mathrm{C}$ & & & 2,9652 & 0,4230 & 1,8705 & 0,6186 \\
\hline INDI_EVI & 16,7204 & $0,0000 *$ & 10,2265 & 0,2233 & 12,7468 & $0,0784^{* *}$ \\
\hline VAR_AT & 0,2868 & 0,8186 & $-0,0326$ & 0,9752 & 0,0931 & 0,9277 \\
\hline VAR_LL & 0,0825 & 0,7084 & 0,1976 & 0,2998 & 0,1731 & 0,3521 \\
\hline $\mathrm{R}^{2}$ & 0,0239 & & 0,5024 & & 0,0223 & \\
\hline $\mathrm{R}^{2}$ Ajustado & 0,0122 & & 0,4072 & & 0,0004 & \\
\hline SQ Regr & 10,4301 & & 8,0800 & & 8,0430 & \\
\hline SQ Res & 18058,78 & & 7,6854 & & & \\
\hline DW & 0,6297 & & 0,9789 & & 0,8817 & \\
\hline AIC & 7,5448 & & 7,1668 & & & \\
\hline SIC & 7,6004 & & 7,6854 & & & \\
\hline IR & & & & & 8,0010 & \\
\hline
\end{tabular}

* Significativo a $1 \%$. ** Significativo a $10 \%$.

Fonte: Dados da pesquisa.

Analisando os dados obtidos com a regressão, nota-se que o "Índice de evidenciação" é significativo a $1 \%$, enquanto que os demais não possuem significância estatística. Isso indica que de fato a evidenciação de itens relacionados ao capital intelectual influenciam no valor do ROA, como observado no estudo de Basso, Martin e Richieri (2006). Entretanto, ao analisar o $R^{2}$, que mede o poder explicativo das variáveis, constata-se que a relação de causa e efeito é irrelevante, uma vez que justifica apenas $2,39 \%$ da variação do ROA.

Considerando as informações referentes à regressão com efeitos fixos, os resultados revelam que nenhuma das variáveis é significativa. Chama a atenção o fato desse tipo de efeito melhorar o poder explicativo da regressão, com um $\mathrm{R}^{2}$ de $54,24 \%$. Compreendendo que o MQO não é a técnica mais apropriada para estimar o coeficiente dos modelos de efeitos aleatórios, adotou-se o MQG. Essa indicação é dada por Duarte, Lamounier e Takamatsu (2007), considerando que esse tipo de modelo assume que existe correlação entre os erros.

Ao considerar o Teste de Durbin-Watson (DW), observa-se que não há autocorrelação nos modelos sem efeitos ( $D W=0,6297$ ) e com efeitos fixos ( $D W=0,9789$ ). Isso, porque, ambos estão dentro dos parâmetros de uso do teste $\left(d_{L}=0,449<d<d_{U}=\right.$ 1,575) para avaliar a dependência (GUJARATI, 2006). Em relação aos testes de significância, que indicam a qualidade de ajustamento dos modelos, o Akaike infocriterion (AIC) e Schwars Criterion (SIC), indicam que não há um bom ajuste ao considerar o modelo sem efeitos, AIC $(7,5448)$ e o SIC $(7,6004)$, e o modelo com efeitos fixos, AIC $(7,1668)$ e o SIC $(7,66854)$.

Analisando a regressão com efeitos aleatórios, sob a perspectiva do MQG, que aumenta os pesos e reduz o erro, de modo a melhorar a eficiência dos estimadores, o estudo aponta que o "Índice de evidenciação" é significativo a $10 \%$. $\mathrm{O} \mathrm{R}^{2}$ possui um poder explicativo pouco expressivo, de 2,23\%, para um DW que continua dentro dos parâmetros, sugerindo que não há autocorrelação, isso indica que esse tipo de regressão é o mais adequado. 
Ao se considerar a não significância das variáveis de controle (variação do AT e LL), constata-se que o "Índice de evidenciação" impacta no ROA, para um p-value de 0,0784 ( $\alpha=$ $10 \%)$, corroborando com os estudos de Firer e Willians (2003), Chen, Cheng e Hwang (2005), Basso, Martin e Richieri (2006), Vieira et al. (2012). Apesar disso, o poder de ajustamento do modelo foi expressivamente baixo, demonstrando que a relação de causa e efeito proposta explica muito pouco. Tal fato pode ter ocorrido em razão de se ter analisado apenas os instrumentos de evidenciação obrigatórios e que outras variáveis não pesquisadas podem deter um maior poder explicativo, como a classificação setorial (MAÇAMBANNI et al., 2012).

Observando a atividade principal desenvolvida pelas empresas estudadas detectouse que, das 13 empresas analisadas, oito delas compõe o setor de utilidade pública, com atividades específicas na distribuição de energia elétrica. Entendendo que esse enquadramento pode influenciar ou distorcer os achados, realizou-se um recorte setorial das empresas, o que resultou em duas amostras: uma com oito empresas de energia e outra com cinco empresas diversas. Tudo isso com o intuito de estimar de novos modelos, como apresentado na Tabela 4.

Tabela 4: Modelos estimados para as oito empresas

\begin{tabular}{|c|c|c|c|c|c|c|}
\hline \multirow[b]{2}{*}{$\begin{array}{l}\text { Variáveis } \\
\text { C }\end{array}$} & \multicolumn{2}{|c|}{$\begin{array}{l}\text { MQO Agrupado } \\
\text { (sem efeitos) }\end{array}$} & \multicolumn{2}{|c|}{ MQO com Efeitos Fixos } & \multicolumn{2}{|c|}{$\begin{array}{l}\text { MQG com Efeitos } \\
\text { Aleatórios }\end{array}$} \\
\hline & Coef. & $p$-value & $\begin{array}{c}\text { Coef. } \\
3,9343\end{array}$ & $\begin{array}{c}\text { p-value } \\
0,3484\end{array}$ & $\begin{array}{c}\text { Coef. } \\
-1,6921\end{array}$ & $\begin{array}{c}\text { p-value } \\
0,7143\end{array}$ \\
\hline INDI_EVI & 14,8865 & $0,0000^{*}$ & 1,0016 & 0,9251 & 15,9766 & 0,1291 \\
\hline VAR_AT & 5,5450 & 0,5562 & 19,1189 & $0,0111^{* *}$ & 14,2791 & $0,0603 * * *$ \\
\hline VAR_LL & 0,0024 & 0,9921 & 0,1770 & 0,3862 & 0,1718 & 0,4091 \\
\hline$R^{2}$ & 0,0810 & & 0,6427 & & 0,0766 & \\
\hline $\mathrm{R}^{2}$ Ajustado & 0,0628 & & 0,5455 & & 0,0489 & \\
\hline SQ Regr & 11,2215 & & 7,8131 & & 8,2622 & \\
\hline SQ Res & 12718,25 & & 4944,67 & & & \\
\hline DW & 0,7675 & & 1,1019 & & 0,9110 & \\
\hline Akaike & 7,7019 & & 7,1418 & & & \\
\hline Schwarz & 7,7782 & & 7,7266 & & & \\
\hline IR & & & & & 8,5780 & \\
\hline
\end{tabular}

* Significativo a $1 \%$. ** Significativo a $5 \% . * * *$ Significativo a $10 \%$.

Fonte: Dados da pesquisa.

Similarmente aos achados para as 13 empresas, a regressão agrupada também se mostra como significativa a $1 \%$, enquanto que os demais continuam sem significância estatística, com um $\mathrm{R}^{2}$ de $8,1 \%$ e um DW 0,7675. Ao considerar os efeitos fixos e aleatórios, o "Índice de evidenciação" não é significativo, apesar da variação do AT ser estatisticamente significativa a 5\% (MQO com efeitos fixos) e 10\% (MQG efeitos aleatórios). Isso sugere que analisar um único setor não melhora o poder explicativo do modelo, o que pode ser justificado pelo número de observações analisadas (104) e a relação não prevista com a variação do AT.

De modo complementar, estimaram-se ainda os modelos para o agrupamento das demais empresas, como exibido na Tabela 5. Esse outro grupo de empresas está composto por empresas de setores de atuação diversos: instituição financeira (Banco Bradesco), material de construção (Eternit), siderurgia (Gerdau), material de transporte e rodoviário (Fras-Le e Randon). 


\section{(9REUNIR}

Tabela 5: Modelos estimados para as cinco empresas

\begin{tabular}{|c|c|c|c|c|c|c|}
\hline & \multicolumn{2}{|c|}{$\begin{array}{l}\text { MQO Agrupado } \\
\text { (sem efeitos) }\end{array}$} & \multicolumn{2}{|c|}{ MQO com Efeitos Fixos } & \multicolumn{2}{|c|}{$\begin{array}{l}\text { MQG com Efeitos } \\
\text { Aleatórios }\end{array}$} \\
\hline $\begin{array}{l}\text { Variáveis } \\
\text { C }\end{array}$ & Coef. & p-value & $\begin{array}{c}\text { Coef. } \\
-5,3909\end{array}$ & $\begin{array}{c}\text { p-value } \\
0,2796\end{array}$ & $\begin{array}{c}\text { Coef. } \\
10,8242\end{array}$ & $\begin{array}{l}\text { p-value } \\
0,0078^{*}\end{array}$ \\
\hline INDI_EVI & 17,9565 & $0,0000 *$ & 32,3820 & $0,0019 *$ & $-0,0920$ & 0,9897 \\
\hline VAR_AT & 0,2007 & 0,8561 & 0,4747 & 0,4957 & 0,1215 & 0,8669 \\
\hline VAR_LL & 0,7976 & 0,2042 & 0,9618 & $0,0116 * *$ & 1,2086 & $0,0044^{*}$ \\
\hline $\mathrm{R}^{2}$ & $-0,4145$ & & 0,7337 & & 0,1281 & \\
\hline $\mathrm{R}^{2}$ Ajustado & $-0,4600$ & & 0,6213 & & 0,0853 & \\
\hline SQ Regr & 9,1040 & & 4,6360 & & 5,5461 & \\
\hline SQ Res & 5138,826 & & 967,1833 & & & \\
\hline DW & 0,2983 & & 1,2187 & & 0,6871 & \\
\hline Akaike & 7,3003 & & 6,1532 & & & \\
\hline Schwarz & 7,4007 & & 6,5273 & & & \\
\hline IR & & & & & 5,8272 & \\
\hline
\end{tabular}

* Significativo a $1 \%$. *** Significativo a $5 \%$.

Fonte: Dados da pesquisa.

Confirmando os achados obtidos para as 13 e 8 empresas, os dados da regressão agrupada mostra-se significativo a $1 \%$, enquanto que os demais continuam sem significância estatística. $O$ estudo indica um $\mathrm{R}^{2}$ de $-41,45 \%$ e um DW de 0,2983. Esses valores sugerem, respectivamente, que há uma relação inversa, ou seja, à medida que aumenta o "Índice de evidenciação", o valor do ROA diminui, e pelo DW, constata-se que há autocorrelação.

Ao tratar dos efeitos fixos, o "Índice de evidenciação" é significativo a $1 \%$, ao passo em que a variação do LL é estatisticamente significativa a $5 \%$, com um $R^{2}$ de $73,37 \%$. Desse modo, o valor explicativo do ROA também é influenciado por uma variável de controle, que foi incluída apenas com o intuito de controlar os efeitos espúrios. Quanto aos efeitos aleatórios, os dados apontam que a variação do $L L$, são significativas a $1 \%$, para um $R^{2}$ de $12,81 \%$. Isso sugere que olhar para um grupo pequeno de empresas não contribui significativamente com o poder explicativo dos modelos, o que pode ser justificado pelo número de observações (65) obtidas em um painel curto.

Com base nos modelos estimados, constata-se que quanto maior o "Índice de evidenciação", maior o ROA (FIRER; WILLIANS, 2003; CHEN; CHENG; HWANG, 2005; BASSO; MARTIN; RICHIERI, 2006; VIEIRA et al., 2012), embora seja observado um baixo poder explicativo, e a publicação de informações pertinentes ao capital intelectual não sejam obrigatórias (BACKES; OTT; WIETHAEUPER, 2005). Isso é observado quando da análise por meio do MQG com efeitos aleatórios das 13 empresas e do MQO sem efeitos das oito empresas de energia elétrica. Ao passo em que quanto maior o "Índice de evidenciação", menor é o ROA ao analisar as cinco empresas, com o MQO sem efeitos.

\section{CONSIDERAÇÕES FINAIS}

O estudo objetivou analisar se há relação entre a evidenciação do capital intelectual e a rentabilidade dos ativos das empresas de capital aberto, listadas pelo Guia 2012 da Você 


\section{(9REUNIR}

S/A, entre as "Melhores empresas para você trabalhar". Para a realização do estudo, tomouse como base a concepção de Perez e Famá (2006), bem como as métricas de capital intelectual enumeradas por Maçambanni et al. (2012) e o desempenho financeiro (ROA), abordado por Vieira et al. (2012).

Com a construção do "Índice de evidenciação", constatou-se que as empresas divulgaram $61,48 \%$ das informações sobre o capital intelectual nos RA, apesar de adotarem as DEM (8,97\%) e NE (29,55\%) como fonte de evidenciação. Ponderando a respeito do número de itens divulgados nas DEM, por empresas, destacam-se: Banco Bradesco (12,98\%), Randon (8,84\%) e Gerdau (8,05\%). Ademais, predomina a evidenciação do CE $(38,96 \%)$ e $\mathrm{CH}$ $(36,92 \%)$, e 50,52\% das informações publicadas são quantitativas. Logo, destaca-se a carência de informações financeiras auditadas sobre o capital intelectual, tanto nas DEM como em NE, o que limita a tomada de decisão.

Considerando a análise das 13 empresas, o uso dos MQG com efeitos aleatórios se mostra como o mais adequado para explicar a relação proposta, quando se compara com os modelos sem efeitos e com efeitos fixos. As estimativas também indicam que o "Índice de evidenciação" investigado chega a impactar significativamente no valor do ROA, apesar de apresentar um poder explicativo pequeno (2,23\%). Nesse contexto, destaca-se que o poder explicativo da relação proposta pode ser melhorado com a inclusão dos itens que compõem as demonstrações voluntárias, na determinação do "Índice de evidenciação", e que a sua avaliação pode ser potencializada com o uso da variável de setor de atuação, como controle.

Ao verificar se as estimativas poderiam ter um poder explicativo mais expressivo, por setor, as empresas foram segregadas em: energia elétrica e diversos. A mesma revelou que ao adotar o MQO sem efeito, que ambos apresentam 1\% de significância. Nas empresas do setor de energia, destaca-se um poder explicativo de $8,1 \%$, ao passo que o grupo composto por empresas de setores diversos indica um poder explicativo inverso $(-41,45 \%)$. Esses fatos sugerem que a combinação de setores diferentes pode aumentar o poder explicativo das estimativas, quando se considera um novo recorte amostral.

Respondendo ao problema de pesquisa, observa-se que há uma relação significativa entre a evidenciação de itens de capital intelectual e a rentabilidade dos ativos das empresas de capital aberto, listadas pelo Guia 2012 da Você S/A, entre as "Melhores empresas para você trabalhar". Nesse contexto, quanto maior o número de itens divulgados sobre o capital intelectual, maior tende a ser o indicador do ROA. Já ao agrupar as organizações por setores, também se observa uma relação significativa, mas inversa, ou seja, quanto maior o número de itens divulgados sobre o capital intelectual, menor o indicador de rentabilidade dos ativos.

Ante ao exposto, sugere-se fazer uso do índice de $Q$ de Tobin, bem como estabelecer relações entre as características de gerenciamento do conhecimento, aprendizado interorganizacional e traços de liderança, com o desempenho organizacional. Ademais, pode-se realizar estudos em outros segmentos ou com empresas listadas na "Em Boa Companhia" ou no "Índice de Sustentabilidade Empresarial" da B3. Também cabe analisar os relatórios empresariais de publicação voluntárias, de modo a identificar se esses instrumentos são mais representativos em termos de evidenciação e se ajudam a explicar a relação proposta. 


\section{(9REUNIR}

\section{REFERÊNCIAS}

ANTUNES, M. T. P.; LEITE, R. S. Divulgação de informações sobre ativos intangíveis e sua utilidade para analistas de investimentos. Revista Universo Contábil, Blumenau, v. 4, n. 4, p. 22-38, out./dez. 2008.

ASSAF NETO, A. Finanças corporativas e valor. 3ạ ed. São Paulo: Atlas, 2007.

ASSAF NETO, A.; LIMA, F. G.; ARAÚJO, A. M. P. Uma proposta metodológica para o cálculo do custo de capital no Brasil. Revista de Administração, São Paulo, v. 43, n. 1, p. 72-83, jan./mar. 2008.

BACKES, R. G.; OTT, E.; WIETHAEUPER, D. Informações sobre Capital Intelectual Evidenciadas pelas Companhias Abertas Listadas em Nível 1 de Governança Corporativa da Bovespa. In: Congresso USP de Controladoria e Contabilidade, 2, 2005, São Paulo. Anais eletrônicos... São Paulo: Fipecafi, 2005.

BASSO, L. F. C.; MARTIN, D. M. L.; RICHIERI, F L. O impacto do capital intelectual no desempenho financeiro das empresas brasileiras. In: Congresso USP de Controladoria e Contabilidade, 3, 2006, São Paulo. Anais eletrônicos... São Paulo: Fipecafi, 2006.

BM\&FBOVESPA - Bolsa de Mercadorias \& Futuros da Bolsa de Valores de São Paulo. Disponível em: http://www.bmfbovespa.com.br/Cias-Listadas/EmpresasListadas/BuscaEmpresaListada.aspx?idioma=pt-br. Acesso em: 18 mar. 2013.

BONTIS, N. Intellectual capital: an exploratory study that develops measures and models. Management Decision, v. 36, n. 2, p. 63-76, 1998.

BONTIS, N. Assessing knowledge assets: a review of the models used to measure intellectual capital. International Journal of Management Reviews, v. 3, n. 1, p. 41-60, 2001.

BONTIS, N.; FITZ-ENZ, J. Intellectual capital ROI: a causal map of human capital antecedents and consequents. Journal of Intellectual Capital, v. 3, n. 3, p. 223-247, 2002.

BRAMMER, S.; PAVELIN, S. Factors influencing the quality of corporate environmental disclosure. Business Strategy and the Environment, v. 17, p. 120-136, 2008.

CHEN, M. C.; CHENG, S. J.; HWANG, Y. An empirical investigation of the relationship between intellectual capital and firms' market value and financial performance. Journal of intellectual capital, v. 6, n. 2, p. 159-176, 2005. 


\section{(9)REUNIR}

COLAUTO, R. D; BEUREN, I. M. Avaliação do capital intelectual na perspectiva da tridimensionalidade da linguagem contábil. Base - Revista de Administração e Contabilidade da UNISINOS, São Leopoldo, v. 2, n. 2, p. 85-101, mai./ago. 2005.

COUTO, P. B. Ativos intangíveis e o desempenho econômico das empresas do novo mercado. 2009. 134 fls. Dissertação (Mestrado em Contabilidade e Controladoria). Universidade Federal de Minas Gerais, Belo Horizonte, 2009.

CRICELLI, L; GRIMALDI, M.; HANANDI, M. How assessing intellectual capital in ICT companies: a new model and an empirical study from Jordan. International Journal of Engieenering and Industrial Management, v. 1, n. 3, p. 51-73, 2011.

DUARTE, P. C.; LAMOUNIER, W. M.; TAKAMATSU, R. T. Modelos econométricos para dados em painel: aspectos teóricos e exemplos de aplicação à pesquisa em contabilidade e finanças. In: Congresso USP de Iniciação Científica em Contabilidade, 4, 2007, São Paulo. Anais eletrônicos... São Paulo: Fipecafi, 2007.

DYE, R. A. An Evaluation of "Essays on Disclosure" and the Disclosure Literature in Accounting. Journal of Accounting and Economics, v. 32, p. 181-135, 2001.

EDVINSSON, L.; MALONE, M. S. Capital intelectual: descobrindo o valor real de sua empresa pela identificação de seus valores internos. São Paulo: Makron Books, 1998.

FIRER, S.; WILLIAMS, S. M. Intellectual capital and traditional measures of corporate performance. Journal of intellectual capital, v. 4, n. 3, p. 348-360, 2003.

GASPARETTO, V. O papel da contabilidade no provimento de informações para a avaliação do desempenho empresarial. Revista Contemporânea de Contabilidade, Florianópolis, v. 6, n. 3, p. 11-40, jul./dez. 2004.

GUJARATI, D. N. Econometria básica. Rio de Janeiro: Elsevier, 2006.

HAIR JR, J. F. et al. Análise multivariada de dados. 6. ed. Porto Alegre: Bookman, 2009.

HENDRIKSEN, E. S.; VAN BREDA, M. Teria da contabilidade. São Paulo: Atlas, 2009.

LAMBERT, R.; LEUZ, C.; VERRECCHIA, R. E. Accounting information, disclosure and the cost of capital. Working paper, Wharton, University of Pennsylvania, 2006. Disponível em: http://fic.wharton.upenn.edu/fic/papers/06/0620.pdf. Acesso em: 02/05/2014.

LEV, B; DAUM, J.H. The dominance of intangible assets: consequences for enterprise management and corporate reporting. Measuring business excellence, v. 8, n. 1, p. 6-17, 2004. 


\section{(9)REUNIR}

MAÇAMBANNI, M. V. et al. Relação entre o nível de disclosure do capital intelectual e características das companhias listadas no índice BM\&FBOVESPA. Revista Alcance Eletrônica, Biguaçu, v. 19, n. 3, p. 345-361, jul./set. 2012.

MATOS, B. et al. A evidenciação voluntária do capital intelectual de natureza social e ambiental da empresa Natura Cosméticos S.A. no período de 2003 a 2007. In: Congresso USP de Controladoria e Contabilidade, 9, 2009, São Paulo. Anais eletrônicos... São Paulo: Fipecafi, 2009.

MEDEIROS, N. C. D.; CRUZ, A. C.; ANDRADE, L. P. Análise de rentabilidade e criação de valor: um estudo de caso em uma empresa brasileira de capital aberto no setor de cosméticos. In: Congresso Virtual Brasileiro de Administração, 6, 2009. Anais... CONVIBRA, 2009.

NAGANO, M. S.; MATHEUS, L. F.; MERLO, E. M. Análise da identificação e da gestão do Capital Intelectual nas usinas sucroalcooleiras. Revista Eletrônica de Administração - REAd, Porto Alegre, v. 11, n. 4, jul./ago. 2005.

NAHAPIET, J; GHOSHAL, S. Social capital, intellectual capital, and the organizational advantage. Academy of Management Review, v. 23, n. 2, p. 242-266, 1998.

NASCIMENTO, E. M. et al. Ativos intangíveis: Análise do impacto do grau de intangibilidade nos indicadores de desempenho empresarial. Enfoque: Reflexão Contábil, Maringá, v. 31, n. 1, p. 37-52, jan./abr. 2012.

OLIVEIRA, J. M.; BEUREN, I. M. O tratamento contábil do capital intelectual em empresas como valor de mercado superior ao valor contábil. Revista de Contabilidade \& Finanças, São Paulo, v. 14, n. 32, p. 81-98, maio/ago. 2003.

PEREZ, M. M.; FAMÁ, R. Ativos intangíveis e o desempenho empresarial. Revista de Contabilidade \& Finanças, São Paulo, v. 17, n. 40, p. 7-24, jan./abr. 2006.

PORTAL do Guia 2012 da Revista Você S/A. Melhores empresas para você trabalhar. Disponível em: http://www.150melhoresempresas.com.br. Acesso em: 18 mar. 2013.

RICHIERI, F L. Capital intelectual e a criação de valor nas empresas brasileiras. 2007. 154 fls. Dissertação (Mestrado em Administração de Empresas). Universidade Presbiteriana Mackenzie, São Paulo, 2007.

SANTIAGO JR, J. R. S.; SANTIAGO, J. R. S. Capital Intelectual: o grande desafio das organizações. São Paulo: Novatec, 2007.

SANTOS, N. N. F. et al. Nível de evidenciação obtido na divulgação das notas explicativas de instrumentos financeiros derivativos segundo a deliberação CVM $n^{\circ}$ 550/08. Revista Contemporânea de Contabilidade, Florianópolis, v. 1, n. 13, p. 175-196, jan./jun. 2010. 


\section{(9)REUNIR}

SCHMIDT, P.; SANTOS, J. L. Avaliação de Ativos Intangíveis. 2ª ed. São Paulo: Atlas, 2009.

SOUZA, B. J. et al. Um estudo sobre evidenciação de capital intelectual nos Relatórios de Administração das 15 maiores distribuidoras de Energia Elétrica do Brasil nos anos de 2006 e 2007. Revista UnB Contábil, Brasília, v. 11, n. 1-2, p. 187-207, jan./dez. 2008.

STEWART, T. A. Capital intelectual: a nova vantagem competitiva das empresas. Rio de Janeiro: Campus, 1998

SVEIBY, K. E. A nova riqueza das organizações: gerenciando e avaliando patrimônios de conhecimento. Rio de Janeiro: Campus, 1998.

UPTON JR, W. S. Challenges from the new economy for business and financial reporting. In: HAND, J. R. M.; LEV, B. Intangible assets: values, measures, and risks. New York, NY: Oxford University Press, 2003.

VASCONCELOS, A. C. F. et al. Formas de atuação de empresas inseridas em redes de cooperação: um estudo exploratório em um consórcio de empresas de base tecnológica. Qu@litas Revista Eletrônica, Campina Grande, v. 8, n. 2, maio/ago. 2009.

VIEIRA, C. B. H. A. et al. Índices de rentabilidade: um estudo sobre os indicadores ROA, ROI e ROE de empresas do subsetor de tecidos, calçados e vestuários listadas na BOVESPA. In: Congresso Virtual Brasileiro de Administração, 8, 2012. Anais... CONVIBRA, 2012.

WERNKE, R.; LEMBECK, M. Avaliação da produtividade dos ativos: estudo de caso em empresa distribuidora de combustíveis. In: Congresso USP de Controladoria e Contabilidade, 6, 2006, São Paulo. Anais eletrônicos... São Paulo: Fipecafi, 2006.

YUTHAS, K, ROGERS, R.; DILLARD, J. F. Communicative action and corporate annual reports. Journal of Business Ethics, v. 41, n. 1-2, p. 141-157, nov./dec. 2002. 